\title{
Thermal biology of newts (Notophthalmus viridescens) chronically infected with a naturally occurring pathogen
}

\author{
Elizabeth Sherman* \\ Natural Sciences, Bennington College, Bennington, VT 05201, USA
}

Received 17 August 2007; accepted 25 September 2007

\begin{abstract}
1. Newts chronically infected with an Ichthyophonus-like organism selected warmer temperatures than healthy newts, consistent with prior work on behavioral fever, though the magnitude of the difference was much greater than reported in other studies.

2. The large difference in selected temperature $\left(>11^{\circ} \mathrm{C}\right)$ may be a consequence of the chronic nature of the Ichthyophonus infection in newts from the field.

3. Healthy newts exhibited a higher thermal tolerance than infected newts, reflecting the greater morbidity of infected newts.

4. Little is known about the course of Ichthyophonus in newts, and the possible consequences of changes in thermal biology are discussed.

(C) 2007 Elsevier Ltd. All rights reserved.
\end{abstract}

Keywords: Newts; Ichthyophonus; Fungal infections; CTMax; Temperature; Amphibians

\section{Introduction}

I undertook this investigation as a consequence of a serendipitous observation I made while collecting newts for another study. It seemed that a preponderance of the animals that I collected in the hottest parts of the pond had obvious lesions. Newts collected in the cooler parts of the pond appeared healthy. The cause of the lesions was identified by the National Wildlife Health Center in Madison, Wisconsin, as an Icthyophonus-like fungus. My own observations and those of others (Herman, 1984; Mikaelian et al., 2000; Green et al., 2002) suggest that the Ichthyophonus-like organism may have been an endemic pathogen in newts for some time, only now becoming more prevalent.

Emerging fungal pathogens have been implicated in worldwide amphibian population declines (Blaustein and Wake, 1990; Daszak et al., 1999; Carey, 2000). Reports suggest that some of the pathogens may have only recently moved into new areas and species while

\footnotetext{
${ }^{*}$ Tel.: + 18024404466 ; fax: +18024404461 .

E-mail address: sherman@bennington.edu
}

others may have been present in the environment and only just increased in incidence or pathogenicity (Daszak et al., 2001; Green et al., 2002; Rachowicz et al., 2005). While morbidity and mortality associated with Ichthyophonus in amphibians have been reported (Mikaelian et al., 2000; Green et al., 2002), the physiological consequences of these infections remain largely unexplored and deserve attention (Wikelski and Cooke, 2006). Moreover, newts are keystone predators in certain ecosystems (Smith, 2006) and their physiological responses to infection may have significant consequences for the composition of those ecosystems.

The thermal biology of amphibians is altered as a consequence of infectious agents. Both anurans (Kluger, 1977; Sherman et al., 1991) and salamanders (Parris et al., 2004) treated with pathogens or subunits isolated from pathogens (such as the lipopolysaccharide, LPS, of bacterial cell walls) select warmer temperatures than uninfected control animals. Furthermore, the thermal tolerance of LPS-treated toads was higher than that of controls even though both groups of animals were maintained at the same febrile temperature (Sherman et al., 1991). In all of these prior experiments, however, 
the animals were exposed to the infectious agent in the laboratory and the responses were acute. What makes this present study particularly interesting is that the infections were acquired naturally rather than in the laboratory and were likely chronic. These considerations coupled with my own observations that the infected newts appeared to select higher temperatures than healthy newts in the wild prompted me to study the thermal biology of infected versus uninfected newts.

I made two predictions. First, infected newts should select warmer temperatures than healthy newts in the laboratory, which would be consistent with prior work noted above. Second, infected newts should tolerate higher temperatures than uninfected newts. Not only did LPS injection increase the thermal tolerance of toads (Sherman et al., 1991) but if, in fact, the infected newts in the present study were seeking out higher temperatures in the field they might be acclimatized to higher temperatures.

\section{Material and methods}

Adult newts, Notophthalmus viridescens, both healthy and infected, were collected during July of 2006, from Wood Pond, a small pond ( $0.9 \mathrm{ha})$ in the foothills of the Taconic Mountains in southern Vermont. I recorded the temperature of the pond water at roughly $20 \mathrm{~cm}$ from the shoreline and at a depth of $10 \mathrm{~cm}$ (places where newts were likely to be found) at several arbitrary positions around the pond on each collection day. The precise temperatures of the water in which apparently healthy and infected newts were collected were not measured, however. The mean pond water temperature $( \pm 1$ SEM) during collection was $26.2 \pm 2.66^{\circ} \mathrm{C}$. Apparently healthy and obviously infected newts were brought back to the laboratory in pond water in separate containers.

Newts were designated as infected or healthy based on the presence or absence of obvious subcutaneous lesions as determined by gross visual inspection. The lesions were consistent with those described elsewhere for Ichthyophonus in amphibians (Herman, 1984; Mikaelian et al., 2000) and ranged from small, typically longitudinally arrayed discrete nodules to larger swellings that involved more than $50 \%$ of the length of the animal (see below). Herman (1984) reported that newts in apparently advanced stages of Ichthyophonus infection exhibited ulcerated lesions that had been secondarily invaded by bacteria. The infected newts that I used in this study did not appear to have such ulcerations. The Ichthyophonus was identified by the National Wildlife Health Center in Madison, Wisconsin, from several newts I submitted. While I did not submit every experimental newt for such histological examination, I was confident in my designation of infected newts as the lesions were obvious and characteristic of Ichthyophonus. I cannot be sure, however, that newts which I designated as healthy did not have subclinical infections.

\subsection{Maintenance of newts in the laboratory}

After collection, newt mass was measured to the nearest $\mathrm{mg}$ in the laboratory. The difference in the mean mass $( \pm 1$ SEM) of healthy $(2.82 \mathrm{~g} \pm 0.1)$ and infected $(2.75 \mathrm{~g} \pm$ $0.23)$ animals was not significant $(p=0.78)$. Healthy and infected newts were housed in separate aquaria containing 8-10 newts per 401 of aged tap water with dry platforms available. The water in the containers was changed every other day. The newts were fed white worms every day until 1-3 days prior to testing. Animals were maintained in the laboratory at a temperature of $24 \pm 0.4{ }^{\circ} \mathrm{C}$ and natural light (roughly 14L:10D) for 7-10 days before testing. While sick and healthy newts may well have selected different temperatures in the field, 7 days is a sufficient duration for temperature acclimation to occur in amphibians (Lutterschmidt and Hutchison, 1997b). Each newt was used only once in either the temperature selection experiments or the thermal tolerance experiments.

\subsection{Temperature selection experiments}

Temperature selection was measured using a thermal gradient similar to that described in Sherman et al. (1991). Briefly, the gradient was produced in an insulated wooden box $\left(140 \times 18 \times 15 \mathrm{~cm}^{3}\right)$ with a steel plate extending $12 \mathrm{~cm}$ from both ends of the box as the floor of the apparatus. The floor was covered with $2-3 \mathrm{~cm}$ of very wet gravel (free water was visible) and the gradient was achieved by placing one end of the steel plate on a hot plate and the other end in a styrofoam box filled with a slurry of dry ice and ethanol. YSI thermistors (accurate to $0.1{ }^{\circ} \mathrm{C}$ ) were embedded in the gravel every $4 \mathrm{~cm}$ and connected to a YSI Model 47 Telethermometer. During experiments, the gradient established ranged from 0 to $40^{\circ} \mathrm{C}$. At the beginning of each temperature selection experiment, a newt was placed individually in the middle of the thermal gradient (at approximately $23{ }^{\circ} \mathrm{C}$ ) under an inverted mesh cup. After $30 \mathrm{~min}$, the cup was lifted and the position of the newt was recorded thereafter every $15 \mathrm{~min}$ for $3 \mathrm{~h}$. The newts were too small for indwelling thermistors so the selected temperature was determined by measuring the position of the thorax of the newts between the 2 closest thermistors in the gravel. Using an external thermometer (Fisher Scientific Precision Thermometer), I had established that the gradient was linear between adjacent thermistors and the position of the newt correlated to the interpolated temperature of the substrate which was recorded as the selected temperature for that reading.

Typically, adult newts are aquatic but there are numerous reports of terrestrial activity among adult newts (see Petranka, 1998, and references therein) and several studies have described the utility of testing them in terrestrial arenas, as I did (Phillips, 1987; Jiang and Claussen, 1993). Moreover, it was not uncommon for me to see newts in this study out of the water on the terrestrial platforms provided in their aquaria. Neither infected nor healthy newts demonstrated 
difficulty moving within the thermal gradient and exhibited no change in mass as a consequence of the $3 \mathrm{~h}$ experiment. To be certain that newts had not become incapacitated at the end of the experiment, following each experiment, I took each newt and placed it in the cold end of the gradient (roughly $5^{\circ} \mathrm{C}$ ). Every newt moved away from the cold end and appeared to have no mobility difficulties. Experiments were performed between 1000 and $1600 \mathrm{~h}$ EDST. I tested 9 healthy and 10 infected newts.

\subsection{Thermal tolerance experiments}

The measure of thermal tolerance used was the critical thermal maximum (CTMax) as described by Lutterschmidt and Hutchison (1997b) and signifies an ecologically appropriate measure of the temperature at which locomotor activity becomes so disorganized that animals are unable to escape from lethal conditions. Each experimental newt was placed individually in a beaker containing $600 \mathrm{ml}$ of aged tap water at room temperature $\left(24 \pm 0.4^{\circ} \mathrm{C}\right)$ and permitted to adjust for $20 \mathrm{~min}$ prior to heating. Then the beaker was heated on a hotplate at $1{ }^{\circ} \mathrm{Cmin}^{-1}$, a rate at which there is no lag between ambient and deep body temperature (Hutchison, 1961). The water was aerated continuously and stirred with a Fisher Scientific Precision Thermometer (accurate to the nearest $0.1^{\circ} \mathrm{C}$ ), which ensured complete mixing of the water. The water temperature at which an experimental newt exhibited abrupt onset of spasms (OS) as described by Lutterschmidt and Hutchison (1997a) was recorded as the CTMax and the newt was promptly removed to room temperature water. All newts recovered almost immediately. The OS is a reliable end-point for CTMax determinations (Lutterschmidt and Hutchison, 1997a), but I also recorded the temperature at which newts appeared to lose the ability to right themselves (loss of the righting response, LRR, a lower level of heat incapacitation). This was a more subjective measure but I include it to facilitate comparisons with data from earlier studies. Ten infected and 10 healthy newts were used in these experiments, which were performed between 1000 and $1600 \mathrm{~h}$ EDST.

\subsection{Extent of lesions}

I wanted to determine whether thermal tolerance was related to the extent of the infection and so after the CTMax experiments, infected newts were anesthetized in MS222 and then laid out on graph paper so that I could measure the span of their lesions. Typically, the lesions were arrayed longitudinally along the newts and could affect one side or both left and right sides. I measured the length of the lesion along the sides in which it was present, added those together and divided by the total length of the animal. This provided a relative index of infection for each newt, which could be used as a predictor of thermal tolerance. It is reasonable to infer that the larger the area affected by the fungus (i.e., the higher the index of infection), the longer the animal had been infected.

\subsection{Statistics}

Differences in mean thermal tolerance between healthy and infected newts were analyzed using the Student's $t$-test with significance set at $p<0.05$.

\section{Results}

Infected newts selected much warmer temperatures than healthy newts (Fig. 1). The mean of the mean selected temperatures of infected newts was $26.1( \pm 0.7){ }^{\circ} \mathrm{C}$ compared with $14.9( \pm 1.0){ }^{\circ} \mathrm{C}$ of healthy newts. In fact, 7 of the 10 infected newts used in these experiments selected temperatures of $30^{\circ} \mathrm{C}$ or more and stayed there for at least $15 \mathrm{~min}$. The warmest temperature selected by any uninfected newt was $26.8^{\circ} \mathrm{C}$.

Healthy newts had a higher CTMax than infected newts (Fig. 2). The mean temperature of the OS ( \pm 1 SEM) of healthy newts of $39.5( \pm 0.1){ }^{\circ} \mathrm{C}$ was significantly greater than that of infected newts with a mean temperature of OS $( \pm 1$ SEM $)$ of $38.9( \pm 0.2){ }^{\circ} \mathrm{C}(t=2.43, \mathrm{df}=18, p=0.025)$. As expected, the mean temperature at the LRR was lower than that of OS but the pattern of healthy animals having a higher thermal tolerance than infected animals persisted (Fig. 3). The mean temperature at LRR was $36.4( \pm 0.2){ }^{\circ} \mathrm{C}$ in healthy newts compared with $34.7( \pm 0.3){ }^{\circ} \mathrm{C}$ in infected newts and was significant $(t=3.99$, $\mathrm{df}=15, p=0.001)$. The sample sizes in the LRR experiments were lower than that of the OS experiments because I was unable to determine loss of righting in 3 newts.

There was no relationship between the extent of the lesion and either measure of thermal tolerance (Fig. 4).

\section{Discussion}

Infected newts selected higher temperatures than healthy newts (Fig. 1), which is consistent with prior work on behavioral fever in ectotherms (Kluger et al., 1975; Sherman et al., 1991). However, the magnitude of the

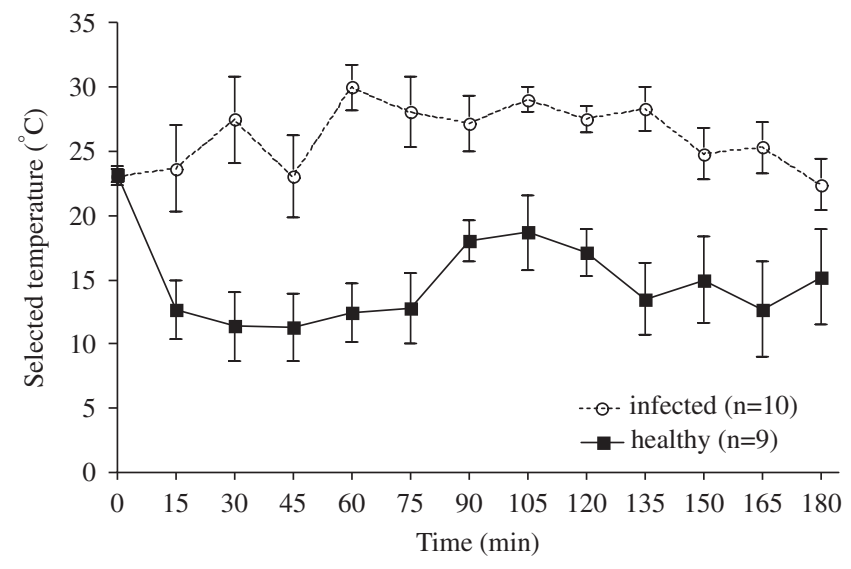

Fig. 1. Mean selected temperatures $( \pm 1$ SEM) over time of infected (open circles) and healthy (closed squares) newts on a thermal gradient. 


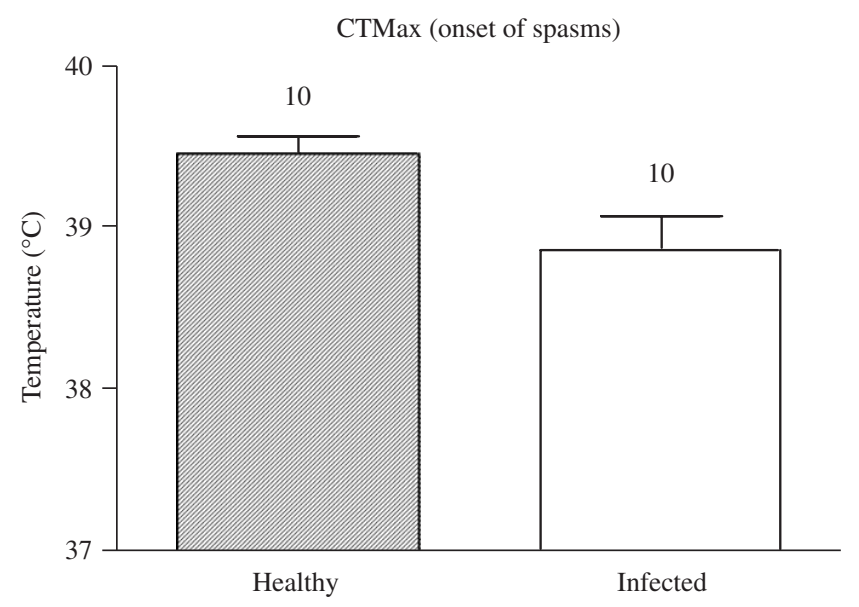

Fig. 2. Mean CTMax ( \pm 1 SEM) of healthy (shaded) and infected (unshaded) newts. The CTMax was measured at the temperature of the onset of spasms (OS). Sample sizes are indicated above each bar.

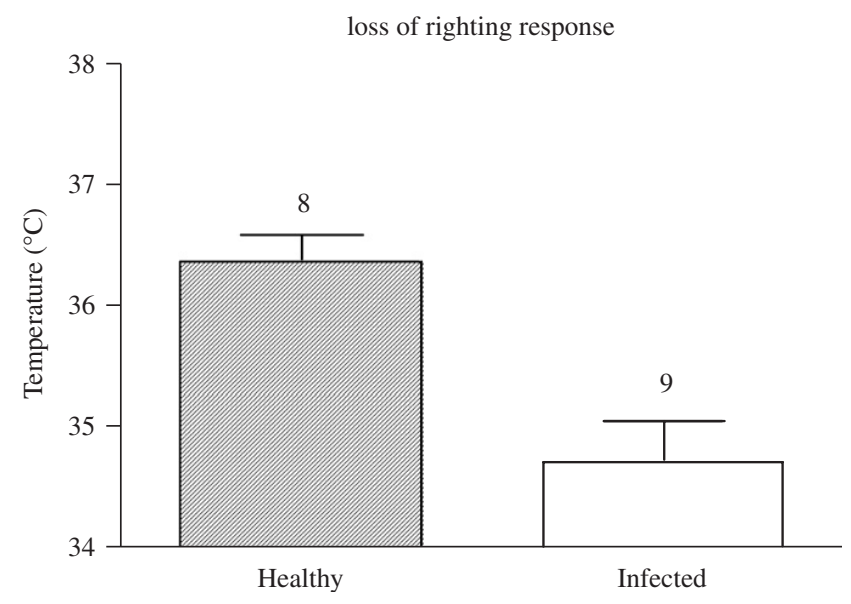

Fig. 3. Mean temperature $( \pm 1$ SEM) of the loss of the righting response (LRR) of healthy (shaded) and infected (unshaded) newts. Sample sizes are indicated above each bar.

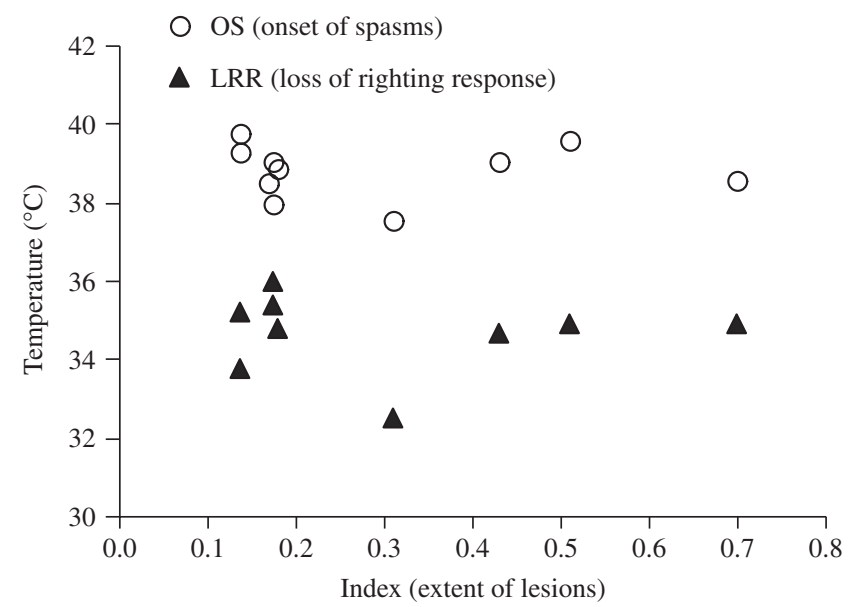

Fig. 4. The temperature of OS (open circles) and LRR (closed triangles) as a function of the index of the extent of lesions (see Section 2 for a description of the index). difference in selected temperatures was much greater than in previous studies. The mean of the mean selected temperature of infected newts was more than $11^{\circ} \mathrm{C}$ higher than that of healthy newts compared with differences of $2-3{ }^{\circ} \mathrm{C}$ in studies of other amphibians (Sherman et al., 1991). While the higher selected temperature of infected newts was consistent with my hypothesis, the large magnitude of the difference was unexpected and may be a consequence of the likely chronic nature of the Ichthyophonus infection in newts from the field. In other studies, animals were infected in the laboratory and the selected temperatures were measured in the acute phase of infection (Parris et al., 2004).

While I could find no reports of the effect of temperature on Ichthyophonus-like infections in amphibians, fish at higher temperatures exhibited a greater incidence of Ichthyophonus than fish at lower temperatures in the wild (Halpenny et al., 2002; Kocan et al., 2003). It is unclear as to how to reconcile the selection of higher temperatures in infected newts (i.e. behavioral fever) with the greater incidence of infection among fish at higher temperatures. On the one hand, some pathogens alter the behavior of host amphibians in such a way as to increase the probability of transmission of the infection (Lefcort and Blaustein, 1995; Parris et al., 2004, 2006), and Ichthyophonus infection may have encouraged newts to seek higher temperatures. Behavioral fever in many ectotherms enables them to survive infections (Kluger, 1991; Kluger et al., 1975). Perhaps the elevated selected temperatures of infected newts promote both transmission of Ichthyophonus and host survival. However, Woodhams et al. (2003) reported that frogs infected with the chytrid pathogen, Batrachochytrium dendrobatidis, were cured when incubated at elevated temperatures. Little is known about the transmission and course of Ichthyophonus-like infections in newts (Mikaelian et al., 2000). Fish must ingest Ichthyophonus-infected prey in order to acquire the organism (Mikaelian et al., 2000). While it is likely that Ichthyophonus has low host specificity (Herman, 1984; Green et al., 2002), the presence of intermediate hosts that facilitate infection in amphibians has not been established (Mikaelian et al., 2000).

I had predicted that Ichthyophonus-infected newts would have a higher CTMax than healthy newts because in an earlier study (Sherman et al., 1991), LPS-treated toads had a higher CTMax than control animals. Sherman et al. (1991) had argued that an increase in thermal tolerance would be advantageous to infected animals if they were seeking warmer microclimates in the wild. In fact, however, infected newts in the present study exhibited lower temperatures of thermal incapacitation than healthy newts (Figs. 2 and 3). The elevated CTMax in LPS-treated toads compared with control toads was exhibited only when the toads had been acclimated at the mean maximum selected temperature of febrile individuals (Sherman et al., 1991). The difference in CTMax between LPS-injected toads and control animals was not significant when both were 
acclimated to normothermic temperatures (Sherman et al., 1991). The newts in this study were acclimated to room temperature $\left(24^{\circ} \mathrm{C}\right)$, several degrees below the mean maximum selected temperature of infected newts $\left(30^{\circ} \mathrm{C}\right)$. But that would not explain why the CTMax of infected newts was lower than that of healthy newts. It is more likely that these chronically infected newts were simply not as robust as healthy individuals. In fact, morbidity of wild captured Ichthyophonus-infected amphibians has been reported (Herman, 1984; Mikaelian et al., 2000; Green et al., 2002). Nevertheless, the CTMax of infected newts $\left(38.9^{\circ} \mathrm{C}\right)$ was well above their mean maximum selected temperature of $30^{\circ} \mathrm{C}$. If there is a benefit to either host or pathogen or both to being in a warmer environment, the thermal tolerance of infected newts is still more than sufficient to accommodate it. The extent of the lesions may not correlate with the degree of morbidity as it did not affect thermal tolerance (Fig. 4).

The consequences of Ichthyophonus for newt populations and the ecosystems in which they are found are unclear. Newts are keystone predators in certain ecosystems and any alteration in their morbidity and mortality may influence the structures of those ecosystems (Smith, 2006). Global climate change that may hasten elevated temperatures in temperate bodies of water makes the relationship between temperature and Ichthyophonus in newts all the more critical to understand (Wikelski and Cooke, 2006).

\section{Acknowledgments}

I thank David Norman, the superb science technician at Bennington College for his construction and maintenance of the thermal gradient. Victor $\mathrm{H}$. Hutchison provided valuable comments on an earlier draft of this paper for which I am grateful. Newts were collected under a permit from the Vermont Fish and Wildlife Department. The Bennington College Animal Care Committee oversaw the care of newts in the laboratory. This work was supported in part by funds of the American Wildlife Research Foundation and the National Science Foundation (OSR-9350540).

\section{References}

Blaustein, A.R., Wake, D.B., 1990. Declining amphibian populations: a global phenomenon? Trends Ecol. Evol. 5, 203-204.

Carey, C., 2000. Infectious disease and worldwide declines of amphibian populations, with comments on emerging diseases in coral reef organisms and in humans. Environ. Health Perspect. 108 (Suppl. 1), 143-150.

Daszak, P., Berger, L., Cunningham, A.A., Hyatt, A.D., Green, D.E., Speare, R., 1999. Emerging infectious diseases and amphibian population declines. Emerg. Infect. Dis. 5, 735-748.

Daszak, P., Berger, L., Cunningham, A.A., Hyatt, A.D., 2001. Anthropogenic environmental change and the emergence of infectious diseases in wildlife. Acta Trop. 103, 116.
Green, D.E., Converse, K.A., Schrader, A.K., 2002. Epizootiology of sixty-four amphibian morbidity and mortality events in the USA, 1996-2001. Ann. NY Acad. Sci. 969, 323-339.

Halpenny, C.M., Kocan, R.M., Winton, J.R., Perry, J.A., Hershberger, P.K., 2002. Elevated temperature exacerbates Ichthyophonus infections in buffalo sculpin. Fish Health Newslett. 30, 18-21.

Herman, R.L., 1984. Ichthyophonus-like infection in newts (Notophthalmus viridescens Rafinesque). J. Wildl. Dis. 20, 55-56.

Hutchison, V.H., 1961. Critical thermal maxima in salamanders. Physiol. Zool. 34, 92-125.

Jiang, S., Claussen, D.L., 1993. The resting and active metabolism of redspotted newts (Notophthalmus viridescens) on land and at simulated winter and summer temperatures. Comp. Biochem. Physiol. 104A, 805-811.

Kluger, M.J., 1977. Fever in the frog Hyla cinerea. J. Therm. Biol. 2, $79-81$.

Kluger, M.J., 1991. Fever: role of pyrogens and cryogens. Physiol. Rev. 71, 93-127.

Kluger, M.J., Ringler, D.H., Anver, M.R., 1975. Fever and survival. Science 188, 166-168.

Kocan, R., Hershberger, P., Winton, J., 2003. Effects of Ichthyophonus on survival and reproductive success of Yukon River chinook salmon. Federal Subsistence Fishery Monitoring Program, Final Project Report No. FIS 01-200. US Fish and Wildlife Service, Office of Subsistence Management, Fishery Information Services Division, Anchorage, Alaska.

Lefcort, H., Blaustein, A.R., 1995. Disease, predator avoidance, and vulnerability to predation in tadpoles. Oikos 74, 469-474.

Lutterschmidt, W.I., Hutchison, V.H., 1997a. The critical thermal maximum: data to support the onset of spasms as the definitive end point. Can. J. Zool. 75, 1553-1560.

Lutterschmidt, W.I., Hutchison, V.H., 1997b. The critical thermal maximum: history and critique. Can. J. Zool. 75, 1561-1574.

Mikaelian, I., Ouellet, M., Pauli, B., Rodrigue, J., Harshbarger, J.C., Green, D.M., 2000. Ichthyophonus-like infection in wild amphibians from Quebec, Canada. Dis. Aquat. Org. 40, 195-201.

Parris, M.J., Davis, A., Collins, J.P., 2004. Single-host pathogen effects on mortality and behavioral responses to predators in salamanders (Urodela: Ambystomatidae). Can. J. Zool. 82, 1477-1483.

Parris, M.J., Reese, E., Storfer, A., 2006. Antipredator behavior of chytridiomycosis-infected northern leopard frog (Rana pipiens) tadpoles. Can. J. Zool. 84, 58-65.

Petranka, J.W., 1998. Salamanders of the United States and Canada. Smithsonian Institution Press, Washington, DC.

Phillips, J.B., 1987. Laboratory studies of homing orientation in the eastern red-spotted newt, Notophthalmus viridescens. J. Exp. Biol. 131, 215-229.

Rachowicz, L.J., Hero, J.-M., Alford, R.A., Taylor, J.W., Morgan, J.A.T., Vredenburg, V.T., Collins, J.P., Briggs, C.J., 2005. The novel and endemic pathogen hypotheses: competing explanations for the origin of emerging infectious diseases of wildlife. Conserv. Biol. 19, 1441-1448.

Sherman, E., Baldwin, L., Fernandez, G., Deurell, E., 1991. Fever and thermal tolerance in the toad Bufo marinus. J. Therm. Biol. 16, 297-301.

Smith, K.G., 2006. Keystone predators (eastern newts, Notophthalmus viridescens) reduce impacts of an aquatic invasive species. Oecologia 148, 342-349.

Wikelski, M., Cooke, S.J., 2006. Conservation physiology. Trends Ecol. Evol. 21, 38-46.

Woodhams, D.C., Alford, R.A., Marantelli, G., 2003. Emerging disease of amphibians cured by elevated body temperature. Dis. Aquat. Org. 55, 65-67. 